Revista Brasileira de Agricultura Irrigada v.13, nº.4, p. 3524 - 3532, 2019

ISSN 1982-7679 (On-line)

Fortaleza, CE, INOVAGRI - http://www.inovagri.org.br

DOI: $10.7127 /$ rbai.v13n4001071

Protocolo 1071.19 - 21/02/2019 Aprovado em 26/07/2019

\title{
ESTRESSE SALINO E USO DE BIOFERTILIZANTE BOVINO NA CULTURA DO TOMATE
}

Maria Vanessa Pires de Souza ${ }^{1}$, Mário de Oliveira Rebouças ${ }^{2}$, Geocleber Gomes de Sousa $^{3}$, Benito Moreira de Azevedo ${ }^{4}$, Geovana Ferreira Goes ${ }^{5}$, Clarissa Lima Magalhães ${ }^{5}$

\section{RESUMO}

O objetivo deste trabalho foi avaliar o efeito da irrigação com água de alta e baixa salinidade em plantas de tomate cultivadas em solo adubado com biofertilizante bovino. O experimento foi conduzido no período de março a abril de 2016, na área experimental da Universidade Federal do Ceará (UFC), Fortaleza, Ceará. O delineamento experimental foi inteiramente casualizado, em esquema fatorial $5 \times 2$, com quatro repetições, referentes a cinco concentrações de biofertilizante: $\mathrm{C} 1$ $=20 \%, \mathrm{C} 2=40 \%, \mathrm{C} 3=60 \%, \mathrm{C} 4=80 \%$ e $\mathrm{C} 5=100 \%$ e dois níveis de salinidade para a água de irrigação $\mathrm{S} 1=0,8 \mathrm{dS} \mathrm{m}^{-1}$ (baixa salinidade) e $\mathrm{S} 2=3,4 \mathrm{dS} \mathrm{m}^{-1}$ (alta salinidade). Foram analisadas a condutividade elétrica do solo (CEes) e o crescimento inicial das plantas utilizando-se as seguintes variáveis: altura de plantas, diâmetro do caule, número de folhas, matéria seca da parte aérea, da raiz e matéria seca total. A irrigação com água de baixa salinidade foi mais eficiente para altura e biomassa das plantas. As concentrações de biofertilizante bovino influenciaram positivamente o crescimento inicial e a biomassa das plantas.

Palavras-chave: Lycopersicon esculentum L., salinidade, insumo orgânico.

\section{SALINE STRESS AND THE USE OF BIOFERTILIZER IN THE TOMATO CROP}

\footnotetext{
ABSTRACT

Objective of this work was to evaluate the effect of irrigation with water of high and low salinity on the initial growth of tomato plants grown in soil fertilized with biofertilizer. The experiment was carried out in the period from March to April 2016, in the experimental area of the Universidade Federal do Ceará, Fortaleza, Ceará. The experimental design was a completely randomized design

${ }^{1}$ Engenheira Agrônoma, Universidade da Integração Internacional da Lusofonia Afro-Brasileira - UNILAB, Redenção, CE. E-mail: vanessa.pires1993@gmail.com

${ }^{2}$ Professor Doutor do Instituto Federal do Ceará - IFCE, Ubajara, CE. E-mail: agromario@gmail.com

${ }^{3}$ Professor Doutor da Universidade da Integração Internacional da Lusofonia Afro-Brasileira - UNILAB, Redenção, CE. E-mail: sousagg@unilab.edu.br

${ }^{4}$ Professor Doutor da Universidade Federal do Ceará - UFC, Fortaleza, CE. E-mail: benitoazevedo@ hotmail.com

5 Graduanda em agronomia, Universidade da Integração Internacional da Lusofonia Afro-Brasileira - UNILAB, Redenção, CE. E-mail: ggoes64@gmail.com; clarissamagalhaes.19@gmail.com
} 
(DIC) in a $5 \times 2$ factorial scheme, with four replications, referring to five concentrations of biofertilizer: $\mathrm{C} 1=20 \%, \mathrm{C} 2=40 \%, \mathrm{C} 3=60 \%, \mathrm{C} 4=80 \%, \mathrm{C} 5=100 \%$ and two salinity levels of irrigation water for $\mathrm{S} 1=0.8 \mathrm{dS} \mathrm{m}^{-1}$ (low salinity) and $\mathrm{S} 2=3.4 \mathrm{dS} \mathrm{m}^{-1}$ (high salinity). We analyzed the electrical conductivity of the soil and the initial growth of plants using the following variables: plant height, stem diameter, number of sheets, dry matter of aerial part, root and total dry matter. Increased concentration of bovine biofertilizer provided higher plant height when irrigated with low salinity water. The bovine biofertilizer was efficient in the growth and accumulation of biomass in tomato plants.

Keywords: Lycopersicon esculentum L., salinity, organic manure.

\section{INTRODUÇÃO}

O tomate (Lycopersicon esculentum) é uma hortaliça da família Solanaceae, cultura anual e de porte médio que se destaca pela sua importância tanto sob o ponto de vista econômico quanto social, o Brasil apresenta condições ótimas para o cultivo desta planta, pois ela apresenta uma ampla adaptação climática. Os fatores que mais influenciam na sua produção são temperatura, umidade atmosférica e do solo e fotoperíodo (MEDEIROS et al., 2012).

O país se destaca na produção desta hortaliça com produção de 4.373.047 t (IBGE, 2018), as principais formas comercializadas são para indústria e para mesa o chamado in natura. A região Nordeste ocupa a última posição entre as regiões produtoras com $526.530 \mathrm{t}$. Um dos fatores que colaboram para estes baixos rendimentos, é a irrigação com água de baixa qualidade (FREIRE et al., 2011).

A escassez da disponibilidade dos recursos hídricos e o aumento da demanda por água, tem resultado na utilização da maioria das fontes de boa qualidade, o que leva muitos produtores a utilizar água de qualidade não convencional e inferior para a irrigação das culturas, fontes essas que apresentam níveis salinos mais elevados, como por exemplo, as águas salinas de poços e de drenagem agrícola (GHEYI et al., 2016). Essas águas apresentam concentrações de sais solúveis elevada, limitando o desenvolvimento e a produtividade de muitas culturas.

A irrigação com água salina, na maioria das vezes, resulta em efeito adverso nas relações solo-água-planta, ocasionando desequilíbrio principalmente nas funções fisiológicas e bioquímicas das plantas, provocando o fechamento dos estômatos, para evitar a perda de água excessiva, e limitações na concentração interna de $\mathrm{CO}_{2}$, o que vai afetar a concentração dos pigmentos envolvidos na fotossíntese, estes eventos vão ter efeito direto na queda do potencial produtivo das plantas cultivadas (GHEYI et al., 2016; TAIZ; ZEIGER, 2017; GOMES et al., 2011).

Ressalta-se a importância da adoção de técnicas de manejo que possibilitem a agricultura nestas regiões afetadas pela salinidade, dentre algumas alternativas para redução dos efeitos nocivos dos sais da água de irrigação nas plantas, está o uso de biofertilizante ou esterco líquido bovino, que tem evidenciado atenuar os efeitos deletérios da salinidade da água de irrigação no crescimento inicial de algumas culturas (SOUSA et al., 2018).

Sousa et al. (2012), estudando o efeito da água salina e do esterco bovino líquido na cultura do milho, verificaram que o aumento do teor salino das águas prejudicou seu crescimento inicial, mas com menos intensidade no solo onde foi aplicado o esterco líquido bovino. Gomes et al. (2015) e Sousa et al. (2017) também constataram efeitos benéficos do biofertilizante bovino em ambiente salino sobre o crescimento inicial de plantas de girassol e gergelim, respectivamente.

Diante desse contexto, o objetivo deste trabalho foi avaliar o crescimento inicial do tomateiro irrigado com água de alta e baixa salinidade em solo adubado com 
biofertilizante bovino com diferentes níveis de diluição.

\section{MATERIAIS E MÉTODOS}

O experimento foi realizado no período de março a abril de 2016, conduzido em ambiente telado, pertencente à Estação Agrometeorológica, da Universidade Federal do Ceará (UFC), em Fortaleza, Ceará $\left(3^{\circ} 45^{\prime} \mathrm{S}\right.$; $38^{\circ} 33^{\prime} \mathrm{W}$ e altitude de $19 \mathrm{~m}$ ). Segundo a classificação de Köppen, a área experimental está localizada em uma região de clima Aw' (tropical chuvoso, muito quente, com chuvas predominantes nas estações do verão e outono). $\mathrm{O}$ material utilizado como substrato apresentava uma mistura de areia e arisco na proporção de 2:1, respectivamente.

A cultura utilizada foi a do tomate (Lyncopersicon esculentum Mill) caqui, híbrido dominador F1 da empresa Topseed. A semeadura foi realizada em vasos plásticos com capacidade de 25 litros. Após o estabelecimento das plântulas, aos cinco dias depois da semeadura (DAS), fez-se o desbaste deixando-se uma planta por vaso.
O delineamento experimental foi inteiramente casualizado em esquema fatorial $5 \times 2$, com quatro repetições. Os tratamentos foram constituídos de cinco concentrações de biofertilizante: $\mathrm{C} 1=20 \%, \mathrm{C} 2=40 \%, \mathrm{C} 3=$ $60 \%, \mathrm{C} 4=80 \%$ e $\mathrm{C} 5=100 \%$, aplicadas em cada vaso em volume correspondente a $10 \%$ do volume do substrato $\left(1,2 \mathrm{~L}\right.$ planta $\left.^{-1}\right)$ irrigada com água de baixa salinidade A1 $(0,8$

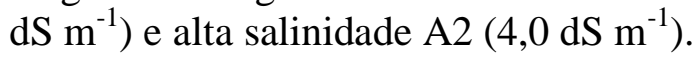

A quantidade dos sais $\mathrm{NaCl}$, $\mathrm{CaCl}_{2} \cdot 2 \mathrm{H}_{2} \mathrm{O}, \quad \mathrm{MgCl}_{2} \cdot 6 \mathrm{H}_{2} \mathrm{O}$, utilizadas no preparo das águas de irrigação foi determinada de forma a se obter a CEa desejada na proporção 7:2:1 obedecendo a relação entre CEa e sua concentração $\left(\right.$ mmol $\left._{c} \mathrm{~L}^{-1}=\mathrm{CE} \times 10\right)$ (RHOADES et al., 2000). A irrigação foi iniciada após o desbaste com uma frequência diária.

O biofertilizante bovino foi preparado a partir de uma mistura de partes iguais de esterco fresco bovino e água não salina $(\mathrm{CEa}=$ $\left.0,8 \mathrm{dS} \mathrm{m}^{-1}\right)$ sob fermentação aeróbia, durante 30 dias, em recipiente plástico, cuja as características químicas estão apresentadas na Tabela 1.

Tabela 1. Composição de macros e micronutrientes essenciais na matéria seca nas concentrações de biofertilizante bovino

\begin{tabular}{|c|c|c|c|c|c|c|c|c|c|c|}
\hline $\mathrm{N}$ & $\mathrm{P}$ & $\mathrm{K}$ & $\mathrm{Ca}$ & $\mathrm{Mg}$ & $S$ & $\mathrm{Na}$ & $\mathrm{Fe}$ & $\mathrm{Cu}$ & $\mathrm{Zn}$ & $\mathrm{Mn}$ \\
\hline \multicolumn{6}{|c|}{ - } & \multicolumn{5}{|c|}{ 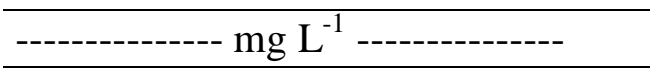 } \\
\hline 0,26 & 0,51 & 1,21 & 0,17 & 3,04 & 0,17 & 0,78 & 47,99 & 0,22 & 16,05 & 10,07 \\
\hline
\end{tabular}

Aos 40 dias após a semeadura (DAS), foram analisadas as seguintes variáveis: altura de plantas (AP) número de folhas (NF), diâmetro do caule (DC), matéria seca da parte aérea (MSPA), matéria seca da raiz (MSR). Para avaliação da matéria seca, as plantas foram acondicionadas em sacos de papel e, em seguida, colocadas para secar em estufa a 60 ${ }^{\circ} \mathrm{C}$, até atingirem valor constante. Após a coleta das plantas, o solo de cada vaso foi homogeneizado e amostras foram utilizadas na determinação da condutividade elétrica do extrato de saturação.

Os dados observados foram submetidos à análise de variância (ANOVA). O teste de Kolmogorov-Smirnov, com nível de $5 \%$ de significância, foi aplicado à normalidade das variáveis: altura de plantas, número de folhas, diâmetro do caule, matéria seca da parte aérea, matéria seca da raiz (MSR) e a condutividade elétrica do extrato de saturação.

Posteriormente, quando significativos pelo teste $\mathrm{F}(\mathrm{p}<0,05)$, os dados referentes aos tipos de biofertilizantes foram submetidos ao teste de comparação de média de Tukey ao nível de $1 \%(* *)$ e $5 \%(*)$ de significância. Para os dados de natureza quantitativos realizou-se análise de regressão, onde as equações que melhor se ajustaram aos dados foram selecionadas com base na significância dos coeficientes de regressão a $1 \%$ e $5 \%$ de significância pelo teste F. Para as análises 
Souza et al.

estatísticas utilizou-se o programa computacional "ASSISTAT 7.7 BETA".

\section{RESULTADOS E DISCUSSÃO}

De acordo com a análise de variância apresentada na Tabela 2 , as águas de diferentes salinidades influenciaram na matéria seca da raiz (MSR) e na matéria seca total (MST). Não houve efeito significativo para as variáveis condutividade elétrica do extrato de saturação do solo (CEes) e pH. As demais variáveis foram influenciadas pelas diferentes concentrações de biofertilizante bovino em nível de significância de $1 \%$ e $5 \%$ pelo teste F. Já para a interação entre os níveis de salinidade e as concentrações de biofertilizante bovino, verificou-se que houve efeito significativo na altura de plantas (AP). Observou-se também o efeito isolado dos níveis salinos e das concentrações de biofertilizantes na matéria seca da parte aérea (MSPA), da raiz (MSR) e na matéria seca total (MST).

Tabela 2. Resumo da análise de variância e médias para a altura da planta (AP), diâmetro caulinar (DC), número de folhas (NF), matéria seca da parte aérea (MSPA) e matéria seca total (MST) em plantas de tomate em função de diferentes níveis de diluição do biofertilizante bovino e, salinidade da água de irrigação.

\begin{tabular}{cccccccccc}
\hline $\begin{array}{l}\text { Fonte de } \\
\text { Variação }\end{array}$ & \multirow{2}{*}{ GL } & \multicolumn{10}{c}{ Quadrado médio } \\
\cline { 2 - 10 } & CEes & AP & DC & NF & MSPA & MSR & MST & pH \\
\hline Biofertilizantes (B) & 4 & $1,37 \mathrm{~ns}$ & $343,96^{* *}$ & $6,01^{*}$ & $20,78^{*}$ & $145,61^{* *}$ & $777,05^{* *}$ & $1485,36^{* *}$ & $0,15 \mathrm{~ns}$ \\
Salinidade (S) & 1 & $0,09 \mathrm{~ns}$ & $28,03 \mathrm{~ns}$ & $2,61 \mathrm{~ns}$ & $0,53 \mathrm{~ns}$ & $38,53 \mathrm{~ns}$ & $294,53^{*}$ & $546,13^{*}$ & $0,43 \mathrm{~ns}$ \\
B x S & 4 & $0,66 \mathrm{~ns}$ & $115,86^{*}$ & $0,75 \mathrm{~ns}$ & $6,28 \mathrm{~ns}$ & $39,61 \mathrm{~ns}$ & $82,61 \mathrm{~ns}$ & $72,80 \mathrm{~ns}$ & $0,31 \mathrm{~ns}$ \\
Resíduo & 20 & 0,73 & 36,6 & 1,4 & 5,93 & 14,4 & 62,1 & 92,03 & 0,13 \\
Total & 29 & - & - & - & - & - & - & - & - \\
\hline C.V. (\%) & & 106,3 & 13,57 & 14,29 & 20,53 & 13,3 & 32,03 & 18,06 & 4,8 \\
\hline
\end{tabular}

$\mathrm{GL}=$ Grau de liberdade; C.V.= Coeficiente de variação; $*$, ** e ns = Significativo a 5\%, $1 \%$ e não significativo pelo teste $\mathrm{F}$, respectivamente. $\mathrm{CEes}=$ condutividade elétrica do extrato de saturação e $\mathrm{pH}=$ potencial de hidrogênio.

De acordo com a Figura $1 \mathrm{~A}$, verificouse que as plantas irrigadas com água de baixa salinidade apresentaram uma maior altura quando comparadas às irrigadas com água de alta salinidade. Em condições de baixa salinidade, as plantas atingiram altura máxima de $55 \mathrm{~cm}$ quando se utilizou-se a concentração de $75,9 \%$ de concentração do biofertilizante. Já sob água de alta salinidade, a altura máxima da planta de $50 \mathrm{~cm}$ foi obtida para a concentração de $100 \%$ de biofertilizante bovino. 
ESTRESSE SALINO E USO DE BIOFERTILIZANTE BOVINO NA CULTURA DO TOMATE


Figura 1. Altura de plantas (A) de tomate em função das concentrações de biofertilizante bovino no solo irrigado com água de baixa $(\triangle)$ e alta de salinidade $(\boldsymbol{\Delta})$, diâmetro do caule $(\mathrm{B})$ e número de folhas $(\mathrm{C})$ em função das concentrações de biofertilizante bovino.

Como mostra a Figura 1B, o modelo linear crescente foi o que melhor se ajustou aos dados. Salienta-se que o insumo orgânico apresentou um efeito positivo para esta variável estudada. É importante ressaltar que a influência positiva de fontes orgânicas sobre as culturas agrícolas está relacionada ao efeito nutricional e consequentemente sobre os índices fisiológicos, permitindo as plantas desenvolvam o seu potencial genético e produtivo, e melhor desenvolvimento vegetal (SANTOS et al., 2014; OLIVEIRA et al., 2014).

Em conformidade com este estudo, Menezes et al. (2015) em condições de campo, avaliando o crescimento inicial do quiabeiro com diferentes doses de esterco bovino, obtiveram um incremento na variável diâmetro do caule em função do aumento das doses do insumo. Lima et al. (2012), também observaram o crescimento linear de plantas de milho com o aumento das concentrações de biofertilizante bovino.

$\mathrm{O}$ número de folhas similarmente ao diâmetro do caule, sofreu efeito significativo a nível de 5\% apenas sob as concentrações de biofertilizante bovino, apresentando um modelo linear crescente, com um coeficiente de determinação de 0,92 . O maior número de folhas foi obtido na máxima concentração de biofertilizante bovino. Esse resultado possivelmente está relacionado com os efeitos positivos do biofertilizante bovino (rico em nitrogênio), ou seja, resultando em maior eficiência das plantas nos processos fotossintéticos e no transporte de solutos orgânicos nos tecidos vegetais (SOUSA et al., 2013). 
Resultados semelhantes foram encontrados por Menezes et al. (2015) onde observaram efeito benéfico do biofertilizante para o número de folhas de quiabeiro submetido a diferentes doses de biofertilizante bovino. Da mesma forma Gomes et al. (2015) constataram esse efeito para plantas de girassol em ambiente salino.

O aumento das concentrações de biofertilizante bovino influenciou positivamente a matéria seca da parte aérea, havendo efeito isolado apenas para esse tratamento a nível de significância de $1 \%$ pelo teste F. O modelo que melhor se ajustou aos dados, foi o polinomial quadrático com $\mathrm{R}^{2}$ de 0,92 na qual a concentração de biofertilizante de $98,4 \%$ proporcionou a maior MSPA, de 32,42 g (Figura 2A).

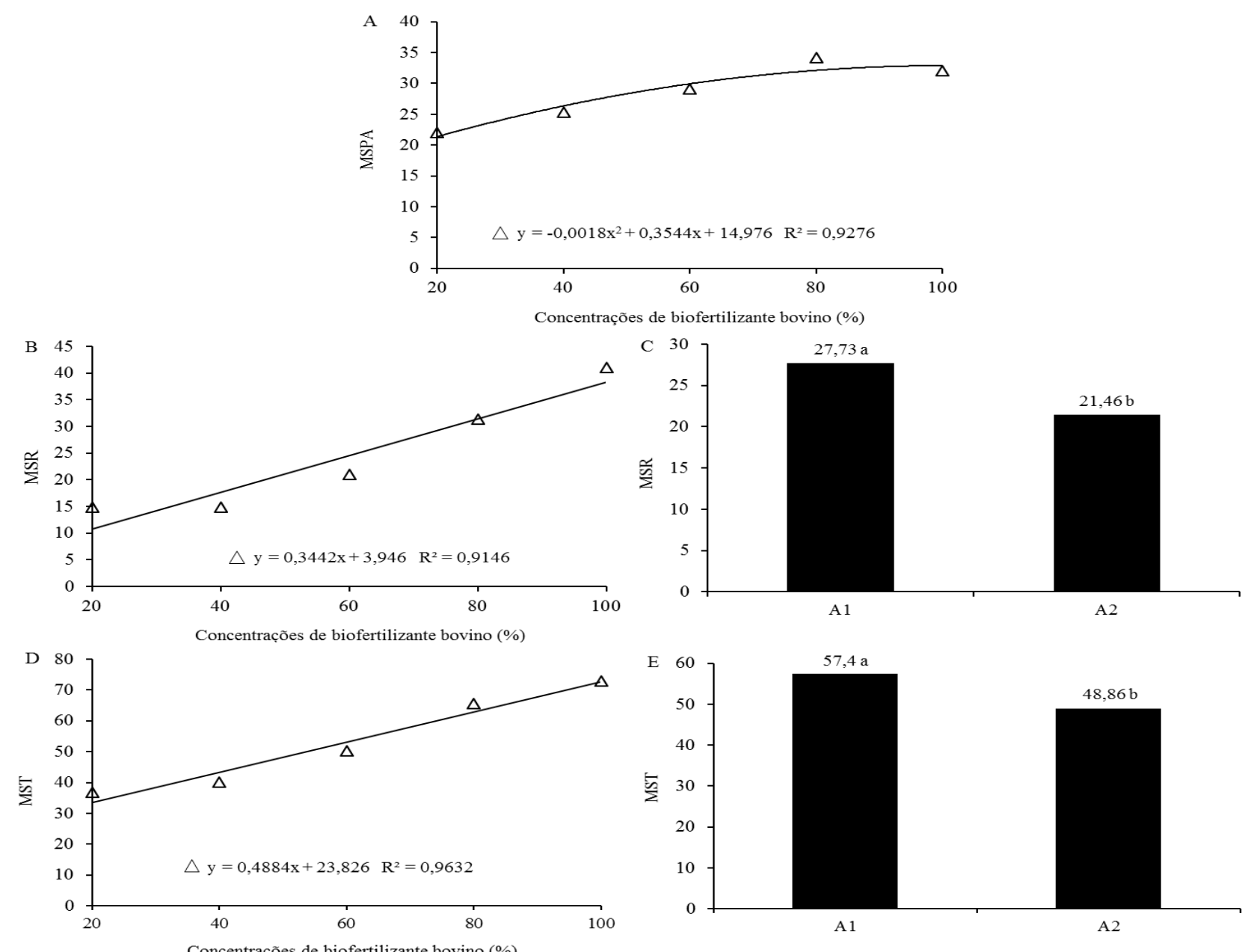

Figura 2. Matéria seca da parte área, MSPA (A), matéria seca da raiz, MSR (B), matéria seca total, MST (D) de plantas de tomate em função das concentrações de biofertilizante bovino no solo, MSR (C) e MST (E) em função da água de irrigação com baixa salinidade A1 $\left(0,8 \mathrm{dS} \mathrm{m}^{-1}\right)$ e alta salinidade A2 $\left(4,0 \mathrm{dS} \mathrm{m}^{-1}\right)$.

Resultados semelhantes onde o biofertilizante estimulou a produção de MSPA foram encontrados por Medeiros et al. (2011) em tomate-cereja, Nascimento et al. (2011) trabalhando com mudas de pimentão em ambiente salino, e Rebouças Neto et al. (2016) estudando o crescimento inicial de plantas de milho, onde observou efeito linear crescente nas concentrações de biofertilizantes sobre a MSPA das plantas.

A partir da análise de regressão para matéria seca da raiz, em função das concentrações de biofertilizante bovino, verificou-se que o modelo linear crescente foi 
o que melhor se ajustou aos dados (Figura 2B). Lima et al. (2012) afirmam que o biofertilizante exerce efeitos benéficos sobre a biomassa das plantas.

Resultados semelhantes ao desse estudo foram observados por Rebouças Neto et al. (2016) em plantas de milho. Já Sousa et al. (2012), observaram tendência polinomial para massa seca da raiz em plantas de milho, com aumento das concentrações de biofertilizante bovino, contrariando esta pesquisa.

Os valores médios apresentados na Figura 2C evidenciam a superioridade do tratamento com água de baixa salinidade, apresentando 27,73g, enquanto a de alta salinidade obteve 21,46g. Em conformidade com estes resultados, Medeiros et al. (2011) concluíram que a massa seca de raiz foi afetada com o aumento da salinidade das águas de irrigação Sousa et al., (2017) constataram que o aumento na salinidade da água de irrigação diminui a matéria seca da raiz em plantas de gergelim. Contrariando esse estudo, Freire et al. (2011) trabalhando em ambiente telado com duas variedades de tomate, não obtiveram efeito significativo com o aumento dos sais na água de irrigação para a variável MSR.

Como verificado para a matéria seca da raiz, a matéria seca total das plantas de tomate foram beneficiadas pelos tratamentos referentes a concentrações de biofertilizantes (Figura 2D). De acordo com a análise de regressão da matéria seca total, nota-se que os dados se ajustaram ao modelo linear crescente. Sousa et al. (2013) afirmam que esse efeito possivelmente está relacionado com a capacidade do biofertilizante estimular a proliferação de microrganismos e solubilizadores de nutrientes essenciais no solo, aumentando a sua disponibilidade às plantas.

Rebouças Neto et al. (2016) também observou uma tendência linear crescente, com incremento de $0,168 \mathrm{~g}$ por planta de MST por aumento unitário nas doses de biofertilizante em plantas de milho. Efeito positivo para a matéria seca total também foram evidenciados por Sousa et al. (2017) trabalhando com biofertilizante bovino em plantas de gergelim, sob estresse salino.

Para os tratamentos utilizando água com maior concentração de sais solúveis observase que as plantas atingiram 48,86g, valor superior foi atingido com o uso de água de baixa salinidade 57,4g (Figura 2E). Em condições salinas, ocorre uma queda do potencial da água no solo, acarretando uma redução da disponibilidade de água às plantas, e assim, a salinidade impõe um maior consumo de energia pelas plantas para a absorção da água e, por consequência, ocorre diminuição na produção de matéria seca (OLIVEIRA et al., 2015).

Em conformidade com este estudo, Nascimento et al. (2017) concluíram que o aumento da salinidade reduziu a biomassa de plantas de maracujazeiro amarelo. Da mesma forma Gomes et al. (2015) observaram resultados semelhantes em plantas de girassol irrigados com água salina.

\section{CONCLUSÕES}

O aumento da concentração do biofertilizante bovino proporcionou maior altura de plantas quando irrigada com água de baixa salinidade.

O biofertilizante bovino foi eficiente no crescimento e no acúmulo de biomassa em plantas de tomate.

\section{REFERÊNCIAS BIBLIOGRÁFICAS}

FREIRE, A. L.; SARAIVA V. P.; J MIRANDA, J. R. P.; BRUNO, G. B. Crescimento, acúmulo de íons e produção de tomateiro irrigado com água salina. Revista Ciências Agrárias, v.31, p.1133-1144, 2011. http://dx.doi.org/10.5433/16790359.2010v31n 4Sup1p1133.

GHEYI, H. R.; SILVA, D. N.; LACERDA, C. F. Manejo da salinidade na agricultura: estudos básicos e aplicados. Fortaleza: INCTSal, 2016.

GOMES, K. R.; AMORIM, A. V.; FERREIRA, F. J.; ANDRADE FILHO, F. L.; LACERDA, C. F.; GOMES-FILHO, E. 
Respostas de crescimento e fisiologia do milho submetido a estresse salino com diferentes espaçamentos de cultivo. Revista brasileira de engenharia agrícola e ambiental, $\quad$ v.15, n.4, 2011. http://dx.doi.org/10.1590/S141543662011000400006.

GOMES, K. R.; SOUSA, G. G.; LIMA, F. A.; VIANA, T. V. A.; AZEVEDO, B. M.; SILVA, G. L. Irrigação com água salina na cultura do girassol (helianthus annuus 1.) em solo com biofertilizante bovino. Irriga, v. 20, n. 4, p. 680-693, 2015. https://doi.org/10.15809/irriga.2015v20n4p68 0 .

IBGE - Instituto Brasileiro de Geografia e Estatística. Produção Agrícola Municipal. Disponível em: <http://www.sidra.ibge.gov.br>. Acesso em: 20 dez. 2018.

LIMA, J. G. A.; VIANA, T. V. A.; SOUSA, G. G.; WANDERLEY, J. A. C.; PINHEIRO NETO, L. G.; AZEVEDO, B. M. Crescimento inicial do milho fertirrigado com biofertilizante. Revista Agropecuária Científica no Semiárido, v.8, n.1, p.39-44, 2012.

http://dx.doi.org/10.30969/acsa.v8i1.208.

MEDEIROS, P. R. F; DUARTE, S. N.; SILVA, Ê. F. F. Eficiência do uso de água e de fertilizantes no manejo de fertirrigação no cultivo do tomateiro sob condições de salinidade do solo. Revista Brasileira de Ciências Agrárias, v. 7, n. 2, 2012. http://dx.doi.org/10.5039/agraria.v7i2a156.

MEDEIROS, R. F.; CAVALCANTE, L. F.; MESQUITA, F. O.; RODRIGUES, R. M.; SOUSA, G. G.; DINIZ, A. A. Crescimento inicial do tomateiro-cereja sob irrigação com águas salinas em solo com biofertilizantes bovino. Revista Brasileira de Engenharia Agrícola e Ambiental, v.15, p.505-511, 2011.

MENEZES, A. S.; SOUZA, M. C. M. R.; SILVA, K. F.; MOREIRA, F. J. C.; SALES,
M. L. M.; CUNHA, C. S. M. Crescimento inicial do quiabeiro (Abelmoschus esculentus) cultivado com diferentes doses de esterco bovino. Agropecuária Científica no Semiárido, v. 10, n. 4, p. 09-13, 2015.

NASCIMENTO, E. S.; CAVALCANTE, L. F.; GONDIM, S. C.; SOUZA, J. T. A.; BEZERRA, F. T. C.; BEZERRA, M. A. F. Formação de mudas de maracujazeiro amarelo irrigados com águas salinas e biofertilizante de esterco bovino. Revista Agropecuária Técnica, v.38, p.1-8, 2017. https://doi.org/10.25066/agrotec.v38i1.28090.

NASCIMENTO, J. A. M.; CAVALCANTE, L. F.; SANTOS, P. D. dos; SILVA, S. A. da; VIEIRA, M. da S.; OLIVEIRA, A. P. Efeito da utilização de biofertilizante bovino na produção de mudas de pimentão irrigadas com água salina. Revista Brasileira de Ciências Agrárias, v. 6, n. 2, p. 258-264, 2011. http://doi.org/10.5039/agraria.v6i2a1060.

OLIVEIRA, F. D A.; GUEDES, R. A.; GOMES, L. P.; BEZERRA, F. M.; LIMA, L. A.; OLIVEIRA, M. K. Interação entre salinidade e bioestimulante no crescimento inicial de pinhão-manso. Revista Brasileira de Engenharia Agrícola e Ambiental, v. 19, n. 3, 2015. http://dx.doi.org/10.1590/18071929/agriambi.v19n3p204-210.

OLIVEIRA, J.R.; GOMES, R.L.; ARAÚJO, A.S.; MARINI, F.S.; LOPES, J.B.; ARAÚJO, R.M. Estado nutricional e produção da pimenteira com uso de biofertilizantes líquidos. Revista Brasileira de Engenharia Agrícola e Ambiental, v.18, p.1241- 1246, 2014.

DOI: http://dx.doi.org/10.1590/18071929/agriambi. v18n12p1241-1246.

REBOUÇAS NETO, M. D. O.; CAMPOS, J. R.; VERAS, C. L.; SOUSA, I. R.; MONTEIRO FILHO, L. R. Crescimento inicial do milho sob diferentes concentrações de biofertilizante bovino. Cadernos Cajuína, v. 1, n. 3, p. 4-14, 2016. 
RHOADES, J. D.; KANDIAH, A.; MASHALI, A. M. Uso de águas salinas para produção agrícola. Campina Grande: UFPB, 2000. 117p. (Estudos FAO - Irrigação e Drenagem, 48).

SANTOS, A. P. G. VIANA; T. V. A.; SOUSA; G. G.; GOMES-DO-Ó; L. M.; AZEVEDO; B. M. SANTOS, A. M. Produtividade e qualidade de frutos do meloeiro em função de tipos e doses de biofertilizantes. Horticultura Brasileira, v. 32, n. 4, p. 409-416, 2014. https://doi.org/10.1590/hb.v32i04.177.

SOUSA, G. G.; MARINHO, A. B.; ALBUQUERQUE, A. H. P.; VIANA, T. V. A.; AZEVEDO, B. M. Crescimento inicial do milho sob diferentes concentrações de biofertilizante bovino irrigado com águas salinas. Revista Ciência Agronômica, v. 43, n. 2, 2012.

SOUSA, G. G.; VIANA, T. V. A.; BRAGA, E. S.; AZEVEDO, B. M.; MARINHO, A. B.; BORGES, F. R. M. Fertirrigação com biofertilizante bovino: efeitos no crescimento, trocas gasosas e na produtividade do pinhãomanso. Revista Brasileira de Ciências Agrárias, v. 8, n. 3, 2013. https://doi.org/10.5039/agraria.v8i3a2288.

SOUSA, R. A., DE LACERDA, C. F., DE AGUIAR, E. M., PRAXEDES, S. C. Efeito da aplicação de biofertilizante líquido no desenvolvimento do sorgo irrigado com água salobra. Científica, v. 46, n. 4, p. 380-397, $2018 . \quad$ http://dx.doi.org/10.15361/19845529.2018v46n4p380-397.

SOUSA, G. G.; FIUSA, J. N.; LEITE, K. N.; SOARES, S. C.; DA SILVA, G. L. Água salina e biofertilizante de esterco bovino na cultura do gergelim. Agropecuária Técnica, v. 38, n. 3, p. 117-124, 2017. https://doi.org/10.25066/agrotec.v38i3.33694.

TAIZ, L.; ZEIGER, E. Fisiologia vegetal. 6. ed. Porto Alegre: Artmed, 2017. 